\title{
The role of trust climate in virtual The role of trust $\begin{gathered}\text { in VTs } \\ \text { int }\end{gathered}$ teams
}

\author{
Taiga Brahm \\ Institute for Business Education and Educational Management, \\ University of St Gallen, St Gallen, Switzerland, and \\ Florian Kunze \\ Institute for Leadership and Human Resource Management, \\ University of St Gallen, St Gallen, Switzerland
}

\begin{abstract}
Purpose - Research testing a complex process model, incorporating moderating and mediating mechanisms associated with virtual team (VT) performance, remains rare. This paper aims to introduce trust climate as a crucial boundary condition for high performance in VTs. It also aims to propose a moderated-indirect model such that the relationship between team goals and task performance is mediated by task cohesion and the relationship between team goals and task cohesion is moderated by trust.
\end{abstract}

Design/methodology/approach - Hypotheses are tested using a longitudinal design with a sample of 50 teams.

Findings - The proposed moderated-indirect model is confirmed. The model explains the indirect relationship between team goal setting and performance transmitted through task cohesion, which is dependent on the level of trust climate.

Research limitations/implications - Although hypotheses were tested in a longitudinal setting, common source bias might be a potential problem for some of the observed relationships. Future research could build on this model for further investigations on more complex theoretical models for VT performance.

Practical implications - This research suggests that managers should emphasize the development of team trust at early stages of collaboration in a VT to reach high performance outcomes.

Societal implications - For VTs, trustful working environments should become even more important in the future, supporting team members' satisfaction in working in VTs.

Originality/value - Through this study, a complex process model for VTs was developed and trust climate established as a prominent context factor for VT success.

Keywords Virtual team, Trust, Team performance, Team cohesion, Team goal setting, Virtual work, Team working

Paper type Research paper

\section{Introduction}

Due to the globalization of the economy and the availability of information and communication technology, virtual teams (VT) have become prevalent in companies (Rack et al., 2011; Horwitz et al., 2006; Gillam and Oppenheim, 2006; Hertel et al., 2004). VTs are defined as "two or more persons who work together on a mutual goal or work assignment, interact from different locations, and therefore communicate and cooperate by means of information and communication technology" (Geister et al.,

The authors would like to acknowledge their colleague Anneloes Raes for her diligent reviewing of their paper.

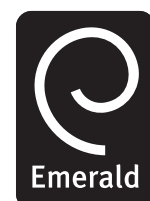

Journal of Managerial Psychology

Vol. 27 No. 6,2012 pp. $595-614$

(C) Emerald Group Publishing Limited 0268-3946

DOI 10.1108/02683941211252446 
JMP 27,6

596
2006, pp. 459-460; see also Bell and Kozlowski, 2002). VTs allow to work independently of time and location, serving the customers and working on innovations seven days-a-week, 24 hours-a-day (Hertel et al., 2004). Organizations benefit from the ability to select their staff regardless of geographical boundaries (Blackburn et al., 2003). In addition, VT work is associated with reduced travel and other costs (Townsend $e$ t al., 1998). However, working in VTs includes several downsides. Compared to face-to-face teams, VTs are more likely to encounter communication and coordination challenges (DeSanctis and Monge, 1999; Rico et al., 2008), possibly leading to time delays when completing the task (Montoya-Weiss et al., 2001). Not only is the task performance hindered, VTs are also more susceptible to atmospheric challenges such as the lack of team cohesion or trust (DeRosa et al., 2004). Thus, virtual project entities often function as a virtual group (loose cooperation, low interdependence, no common goals) rather than a virtual team (close cooperation, high interdependence, common goals) (Katzenbach and Smith, 1993).

As a main contribution, this study aims to investigate the interrelation of a complex chain of input factors, processes, and context factors (Mathieu et al., 2008), in line with Kozlowski and Bell's (2003) organizational systems perspective. Particularly, we want to introduce trust climate as a crucial context factor for the achievement of high performance levels in VTs. Although several studies have investigated the evolvement of trust in VTs (Jarvenpaa et al., 1998; Henttonen and Blomqvist, 2005; Holton, 2001) or the role of trust as an antecedent for VT successes (DeRosa et al., 2004; Sarker and Valacich, 2003), to our knowledge, almost no empirical research looked into its contextual role thus far (for an exception see Jarvenpaa et al. 2004; for general organizational team research, more than 90 percent of the studies have only tested the main associations of trust, Dirks and Ferrin, 2001). Consequently, we want to theoretically derive and empirically test a moderated- mediating model considering trust as a boundary condition for input factors associated with VT team performance.

As main input factor for VT team success, it can be assumed that VT members need to set clear team goals during the team (planning) process in order to ensure future prosperity. Thus, the current study follows the call by Martins and colleagues (2004, p. 821), who stated that the "planning process. . . is a fruitful area for future research on VTs". However, these team goals are not directly related to VT performance but first need to be transferred to team cohesion, which allows a joint cooperation to execute the common goals (in line with the model from Hackman and Morris, 1975). Yet for VTs, it is often difficult to develop high team cohesion based on shared goals as they have less communication and interaction compared to real teams (Blackburn et al., 2003). Although goals are formally set at the beginning of a VT team process, they are not necessarily connected to high team cohesion and ultimately performance as it is difficult for members to become acquainted with the goals, share information and observe each other's work (Zolin et al., 2004). Here, trust climate plays a central boundary role. If a high trust climate is created in the first stage of the VT development process, team goals should be better transferred in joint bonding behaviors (e.g. team cohesion) because the uncertainty and ambiguity of the other team members' behavior is reduced (Dirks and Ferrin, 2001), ultimately favoring performance.

Thus, in sum, we propose a moderated-mediation model as depicted in Figure 1, in which team goal setting is transmitted via team cohesion to team performance, depending on the level of trust among team members. 


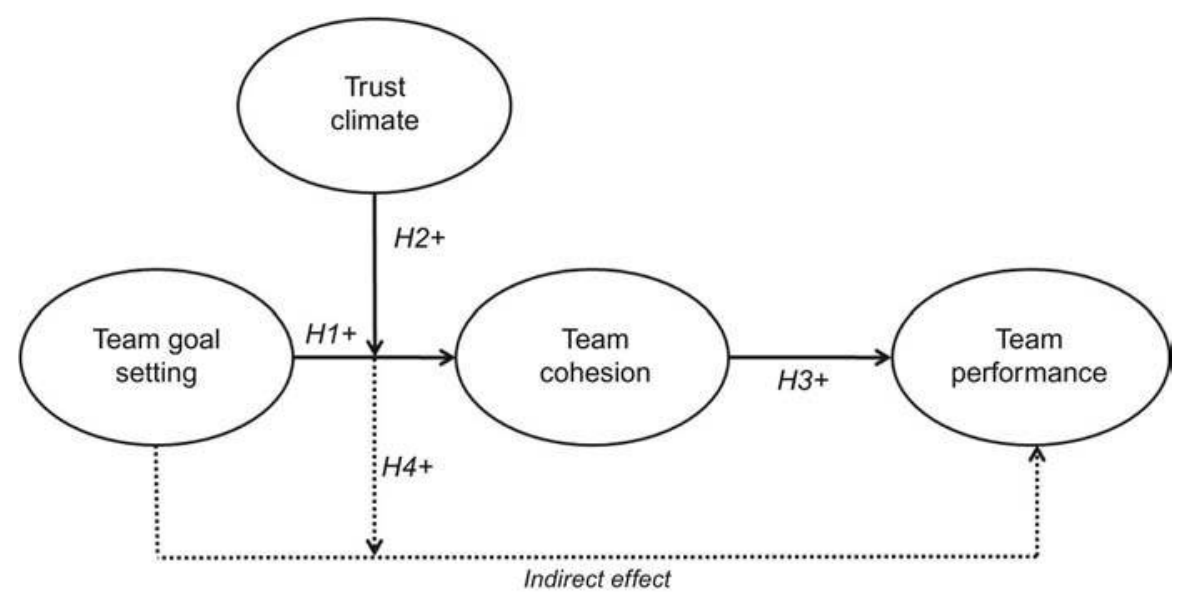

\section{The role of trust in VTs}

Indirect effect

597

In doing so, the current study makes three important theoretical contributions. First, it contributes to VT literature by testing a complex model, explaining the processes and emergent states relating to performance of VTs. As suggested by Martins et al. (2004, p. 823), the current study considers moderating and mediating factors to "develop a richer, more theoretically grounded understanding of the underlying dynamics in VTs". Thus, we provide an empirically tested process model given there are very few only conceptual process models for virtual teams in the literature (Furst et al., 1999; Hertel et al., 2005; Curşeu, 2006).

Specifically, we introduce, as our second contribution, trust climate as a contingency factor in the VT goal setting/performance relationship. A recent review on trust research in VTs highlighted that the role of trust as a contextual factor for processes, emergent states, and VT outcomes is an under-researched area (Mitchell and Zigurs, 2009), suggesting the need to look further into trust as a process. In particular, no study has been published that investigated the contextual role of trust for the goal setting, team cohesion and performance relationship in VTs. Thus, this study should help establish trust as an important moderator. In doing so, we also extend general research on trust in organizations by testing Dirks and Ferrin's (2001) theoretical assumption by that trust is a moderator between determinants and performance rather than an antecedent.

Third, although VTs are distinct from traditional teams, this study also aims to contribute to the general team literature by testing a theoretically grounded model that interconnects team processes, emergent states, and team outcomes. As criticized by Marks et al. (2001), team studies often lack a clear theoretical distinction between these different facets of team development stages, thereby limiting their theoretical and practical implications. Thus, the current study is intended to provide theoretical implications that are also helpful for the further theoretical development of general team research.

In addition to the contribution to the scientific literature, the results of this study should provide companies with practical information on how to reap the benefits of VTs. In particular, the results establish trust as a valuable intervention mechanism that allows virtual entities to reach performance as real virtual teams, rather than being underperforming virtual groups. 
JMP

27,6

598

\section{Hypothesis development}

Team goal setting and team cohesion

As first part of our moderated-mediation model, team goal setting is positively related to team cohesion in VTs. Team goals can be defined as "a future state of affairs desired by enough members of a group to motivate the group works towards the achievement" (Johnson and Johnson, 1987, p. 132). Based on this definition, team goal setting is referring to the process of mutual discussion of and final agreement on common group goals. In VTs, it is more ambitious to implement and maintain common goals because it is more difficult for team members to discuss the goals (Hertel et al., 2004). Nevertheless, through virtual communication and cooperation, team goal setting can occur in VTs. As a second focal construct, the emergent state of team cohesion "refers to an individual's attraction to the group because of shared commitment to the group task" (van Vianen and De Dreu, 2001, p. 100).

Team goal setting is linked to team cohesion through several theoretical routes. Clear team goals allow team members to align their individual goals with team goals (Huang et al., 2002). Thus, it is easier for team members to focus their personal efforts on these common group goals, consequently increasing the overall team cohesion. In a similar vein, common goals are expected to decrease any goal conflicts in the subsequent team development stages (De Souza and Klein, 1995), which might diminish team cohesion. Johnson and Johnson (1987) further argue that cooperative goal setting requires close interaction among team members, thus, facilitating higher team cohesion in the future team development.

These theoretical arguments are supported by empirical results from several studies. In a laboratory study with virtual teams, Huang et al. (2002) reported that the alignment of individual and team goals (i.e. collaborative goal setting) contributed to more cohesive teamwork. This relation between goal setting and team cohesion was also found in studies with traditional teams (Klein and Mulvey, 1995; Wegge, 2000). For instance, in a study with undergraduate students, a significant and positive relation between goal commitment and group cohesion was found (Klein and Mulvey, 1995). We believe that these prior results from laboratory studies and traditional teams can also be transferred to VTs in real work settings and thus propose the following:

H1. Team goal setting is positively related to team cohesion.

\section{Moderating role of team trust}

The relationship between goal setting and team cohesion in VTs likely depends on the boundary condition of trust climate. At the team level, trust can be interpreted as the willingness of a team member "to be vulnerable to the actions of another party based on the expectation that the other will perform a particular action important to the trustor, irrespective of the ability to monitor or control that other party" (Mayer et al., 1995, p. 712). In VTs, compared to face-to-face teams, the development and maintenance of trust is more difficult as some mechanisms of control (e.g. direct control by supervisors) are not available (Jarvenpaa et al., 1998; Peters and Manz, 2007). In addition, only virtual communication is less favorable for trust attitudes (Li et al., 2004). Nonetheless, a climate of trust can also develop through virtual interaction and exchanges among team members, playing an especially important boundary role for the relationship between team goal setting and team cohesion (Wilson et al., 2006). 
In the current study's proposed model, trust is not directly associated with certain team processes as suggested in other studies (Staples and Webster, 2008; Liu et al., 2008; for an overview see Mitchell and Zigurs, 2009) but rather through the way in which VT members interpret certain actions and behaviors (e.g. goal setting).

Dirks and Ferrin (2001) provided theoretical grounding for the moderating role of trust in the relationship between goal setting and team cohesion. They argued that the level of trust in an organizational relationship (e.g. between individuals or between members of a team) is associated with two distinct processes: First, trust climate is related to team members' evaluations of other team members' past or present actions. Second, trust climate also concerns a team member's interpretation of the future actions of another team member. By considering the prior and future actions, trust can reduce or favor the risk and ambiguity in interaction with other parties (e.g. team members).

Transferring the logic of Dirks and Ferrin (2001) to our assumed relationship, the association between goal setting and team cohesion may be more distinct under conditions of high trust climate. Specifically, if employees perceive mutual support from their team members, based on prior actions and future expectations, and are confident that their colleagues behave in a way that is beneficial for the team, team goals might better translate into team cohesion. In a high trust climate condition, team members have higher security that their colleagues pursue the collective goals upon which they initially agreed, which should in turn convert into higher team cohesion. Hence, the trust climate is a boundary condition that reduces uncertainty and allows risk taking to reach common goals in VTs (Peters and Manz, 2007; Zolin et al., 2004).

In contrast, when the trust climate is low, the advancement of team cohesion, initiated by clear goal setting is endangered because uncertainty and ambiguity about the action of team members increase (Dirks and Ferrin, 2001). Instead of working toward collective team goals, team members question the intention of their colleagues and spend significant time monitoring each others' actions (Rico et al., 2008). Furthermore, a low trust climate might also facilitate the emergence of individual utility maximization within VTs. Given team members do not have high confidence that their colleagues indeed invest their efforts for collective team goals, it is highly likely that at least some of them show free-riding behavior (Furst et al., 2004), which will decrease the positive linkage between team goals and team cohesion. Finally, a low trust climate might also facilitate the emergence of conflicts within VTs (Porter and Lilly, 1996) - in particular, debates about the central team goals. These disputes over team goals can ultimately be connected with a less positive association between team goal setting and team cohesion. In light of these factors, the following moderation hypothesis is proposed:

H2. The trust climate in teams moderates the relationship between team goal setting and team cohesion such that the relationship is stronger in teams with a high trust climate than in teams with a low trust climate.

\section{Team cohesion and task performance}

Finally, as last step of the moderated-mediation model the study results are expected to show a positive relationship between team cohesion and task performance. Task performance is defined as the productivity of the team concerning a certain task; it includes the attainment of team goals set by either the team itself or a superior (Hackman, 1987). A positive linkage between team cohesion and task performance

\section{The role of trust in VTs}

599 
JMP

27,6

600 seems intuitively plausible because, if an individual feels a certain bond with his or her team members, the team's productivity will increase (Beal et al., 2003). VTs with high levels of team cohesion will perform more synergetic interaction compared to less cohesive teams. Thus, within teams with significant team cohesion, more effective task-specific communication and workload sharing as well as fewer task-specific conflicts should occur (Barrick et al., 1998). Team cohesion is also related to mutual accountability, enhancing team members' efforts to improve team processes, thereby initiating extra-role helping and employee satisfaction (Kirkman et al., 2004; Hertel et al., 2005). These positive facets of team cohesion are in turn associated with an overall higher task performance.

This relationship is also supported by initial empirical evidence in VT research. Van den Bossche et al. (2006), for example, reported a positive relationship between team cohesion and team effectiveness in a study with 75 teams in a student sample. Similarly, in their field study, Horwitz et al. (2006) found that team cohesion was a key factor (among others) for the success of VTs. Based on this discussion, the following hypothesis is proposed:

H3. Team cohesion is positively related to team performance.

\section{Moderated-mediation hypothesis}

Taken together, the three previous hypotheses suggest a model in which not only the relationship between goal setting and team cohesion, but also the mediated relationship between goal setting and performance depends on the level of trust climate. More specifically, we assume that in VTs, team goal setting is only related to team performance via the intermediation of team cohesion. Only if team goals are associated with close team cohesion, explained by the alignment of individual with team goals (Huang et al., 2002) and diminished goal conflicts (De Souza and Klein, 1995), they are related to performance, through more effective task-specific interaction (Barrick et al., 1998) as well as more extra-role helping (Kirkman et al., 2004). Applying the conceptual argumentation of Dirks and Ferrin (2001), team trust climate should be a prominent boundary condition for this mediating relationship as it reduces potential risk and uncertainty between the team members that might prohibit a strong transmission of goal setting into team cohesion (in turn related to team performance). Thus, we propose the following hypothesis:

H4. The team's trust climate moderates the positively mediated relationship between team goal setting and task performance. The mediated relationship will be more evident in higher levels of team trust climate than in low levels of team trust climate.

\section{Methods}

Sample and procedures

The study took place in a German telecommunication company in the field of vocational education. The participants of the study were apprentices of different vocational professions who spent one part of their apprenticeship in the company and another part in vocational schools. During their first year, 456 apprentices from eight different locations participated in a three-month VT project set up as a computer-supported collaborative learning scenario. Accordingly, the team members 
were scattered across different locations of the company and collaborated via electronic communication devices such as e-mail, discussion fora, wikis, and blogs. The goal of the team project was to develop a multimedia presentation of a subject area relevant to apprentices in their first year.

Ultimately, 91 teams were invited to take part in the current study. To minimize problems of common source bias (Podsakoff $e$ t al., 2003), the study measured the team performance variable with a time lag of eight weeks. In the final results, 50 teams with 124 members provided information from at least two team members at both measurement points and were therefore integrated into our final study sample (team response rate $=46$ percent). These teams consisted of an average 2.52 team members. On average, the apprentices were 19 years old, and 56.9 percent of the respondents were male.

\section{Measures}

If not otherwise stated, all measures were assessed applying a six-point Likert scale ( $1=$ I do not agree at all; $6=$ I totally agree). To justify an aggregation of the measures to the team level, common aggregation statistics were used, such as intraclass correlation statistics (ICC) (Bliese, 2000) and $\mathrm{r}_{\mathrm{wg}}$ (James et al., 1984). Given the small team sizes, the study focused on the significance of the ANOVA comparing the team means, the $\mathrm{ICC}_{1}$, and the $\mathrm{r}_{\mathrm{wg}}$ index of agreement. The $\mathrm{ICC}_{2}$ seems to be inappropriate for this sample as its values depend on team size and tend to be particularly unreliable for small team sizes (Castro, 2002). As a rule-of-thumb, a significant ANOVA indicates that respondents within one team converge in their assessment from members of other groups whereas a median $r_{\mathrm{wg}}$ score of more than 0.70 indicates sufficient agreement of respondents within a group (Bliese, 2000; Kozlowski and Klein, 2000).

Team goal setting. Team goal setting was assessed using the measure provided by Huang et al. (2002), which has also been used with VTs. The measure consisted of six items, such as "Our clearly defined and shared goals represent an opportunity for an exceptional level of achievement." The aggregation of the individual items to the team level was justified by sufficient aggregation statistics $\left(\mathrm{ICC}_{1}=0.19, F[1.56] p<0.042\right.$; median $r_{\mathrm{wg}}=0.87$ ). The Cronbach's alpha of this scale was 0.86 .

Team trust climate. Jarvepaa and Leidner's (1999) measure of trust - originally developed for VTs - was used for this study The scale consists of four items, such as "Overall, the people in my group were very trustworthy." In the current study, individual answers were aggregated to the team level based on satisfactory aggregation statistics $\left(\mathrm{ICC}_{1}=0.18, F\right.$ [1.54] $p<0.048$; median $\left.\mathrm{r}_{\mathrm{wg}}=0.83\right)$. The Cronbach's alpha of this scale was 0.87 .

Team cohesion. Team cohesion was assessed using Chang and Bordia's (2001) scale (three items). Although it had not been used for virtual teamwork before, it did not have to be adapted. A sample item was "My team is united in trying to reach its goal for performance." The aggregation statistics showed sufficient results for aggregating the items to the team level $\left(\mathrm{ICC}_{1}=0.32, F[2.13] p<0.001\right.$; median $\left.\mathrm{r}_{\mathrm{wg}}=0.74\right)$. The Cronbach's alpha for this scale was 0.89 .

Team performance. Team performance was rated by the team members on a scale created by Zellmer-Bruhn and Gibson (2006). The scale consisted of five items, such as "This team achieves its goals." Individual responses were aggregated to the team level based on satisfactory aggregation statistics $\left(\mathrm{ICC}_{1}=0.32, F[2.13] p<0.001\right.$; median $\left.\mathrm{r}_{\mathrm{wg}}=0.81\right)$. The Cronbach's alpha for this instrument was 0.97 .

\section{The role of trust in VTs}

601 
JMP

27,6

602
Controls. The current study also integrated several control variables into the models to account for their potential association with the dependent variable. First, team size might be related to team performance (e.g. Mullen et al., 1991; Wegge et al., 2008) or to team processes, such as cohesiveness (e.g. Ancona and Caldwell, 1992; Bantel and Jackson, 1989). Second, team diversity might be connected to team processes and performance (van Knippenberg and Schippers, 2007). Thus, the current study controlled for age $(1=15-16$ years, $2=17-18$ years, $3=19-20$ years, $4=$ older than 20 years), gender $(1=$ male, $2=$ female), and educational distribution (the type of apprentice program, e.g. IT specialist; office management assistant) within the teams. As all three measures were gauged on a categorical scale, Blau's index of heterogeneity (Blau, 1977) was calculated, which is the most commonly used measure for categorical diversity measures (Harrison and Klein, 2007; Bunderson and Sutcliffe, 2002). Additionally, prior performance was controlled by inserting initial team potential as a control variable (similar to team ability as in Kozlowski and Bell, 2003).

\section{Discriminatory and convergent validity}

To inspect the discriminatory and convergent validity of the four constructs (goal setting, trust climate, team cohesion, and performance), a confirmatory factor analysis was conducted using the AMOS 18 computer package. Following the advice of Hu and Bentler (1998) for sample sizes of less than 200, standardized root mean square residual (SRMR) together with two incremental fit indices - the comparative fit index (CFI, Bentler, 1990) and the incremental fit index (IFI, Bollen, 1989) - was applied to assess the overall model fit. We also report values of the root mean square error of approximation (RMSEA), which should, however, be interpreted with caution because this index has shown strong tendencies to over reject correct models in small samples (Chen et al., 2008). We used the common cutoff value for the two comparative fit indices of .90 (Hu and Bentler, 1998), and for SRMR as well as RMSEA, values should be below .08 for a sufficient model fit (Browne and Cudeck, 1993).

First, a measurement model was specified in which the six goal setting items, the three team cohesion items, the four trust items, and the five performance items were loaded on their respective latent construct. This model showed sufficient fit properties $(\chi 2=167, \mathrm{df}=129 ; \mathrm{CFI}=0.97, \mathrm{IFI}=0.97, \quad \mathrm{SRMR}=0.072, \quad \mathrm{RMSEA}=0.078)$. Furthermore, all factor loadings were above 0.50 and significant at the 0.001 level (see also Figure 2). To inspect the discriminate and convergent validity, a second model was specified in which all items that came from the same data source (goal setting, team cohesion, and trust) loaded on one common factor. The fit of this alternative model was significantly worse compared to the original four-factor model $(\chi 2=257$, $\mathrm{df}=134 ; \quad p<0.001, \quad \mathrm{CFI}=0.89, \quad \mathrm{IFI}=0.89, \quad \mathrm{SRMR}=0.088, \quad \mathrm{RMSEA}=0.137)$. Finally, a third model was specified in which all items loaded onto one common factor; this also had a significantly worse fit $(\chi 2=621$, $\mathrm{df}=135 ; p<0.001 \mathrm{CFI}=$ $0.56, \quad \mathrm{IFI}=0.57, \mathrm{SRMR}=0.136, \mathrm{RMSEA}=0.271)$. Given these results, the hypothesized four-factor model fit the data best as the four constructs are theoretically as well as empirically distinct.

\section{Analytical techniques}

The proposed hypotheses were tested with structural equation models (SEM). Compared to standard regression techniques, SEM has several advantages, such as controlling for 


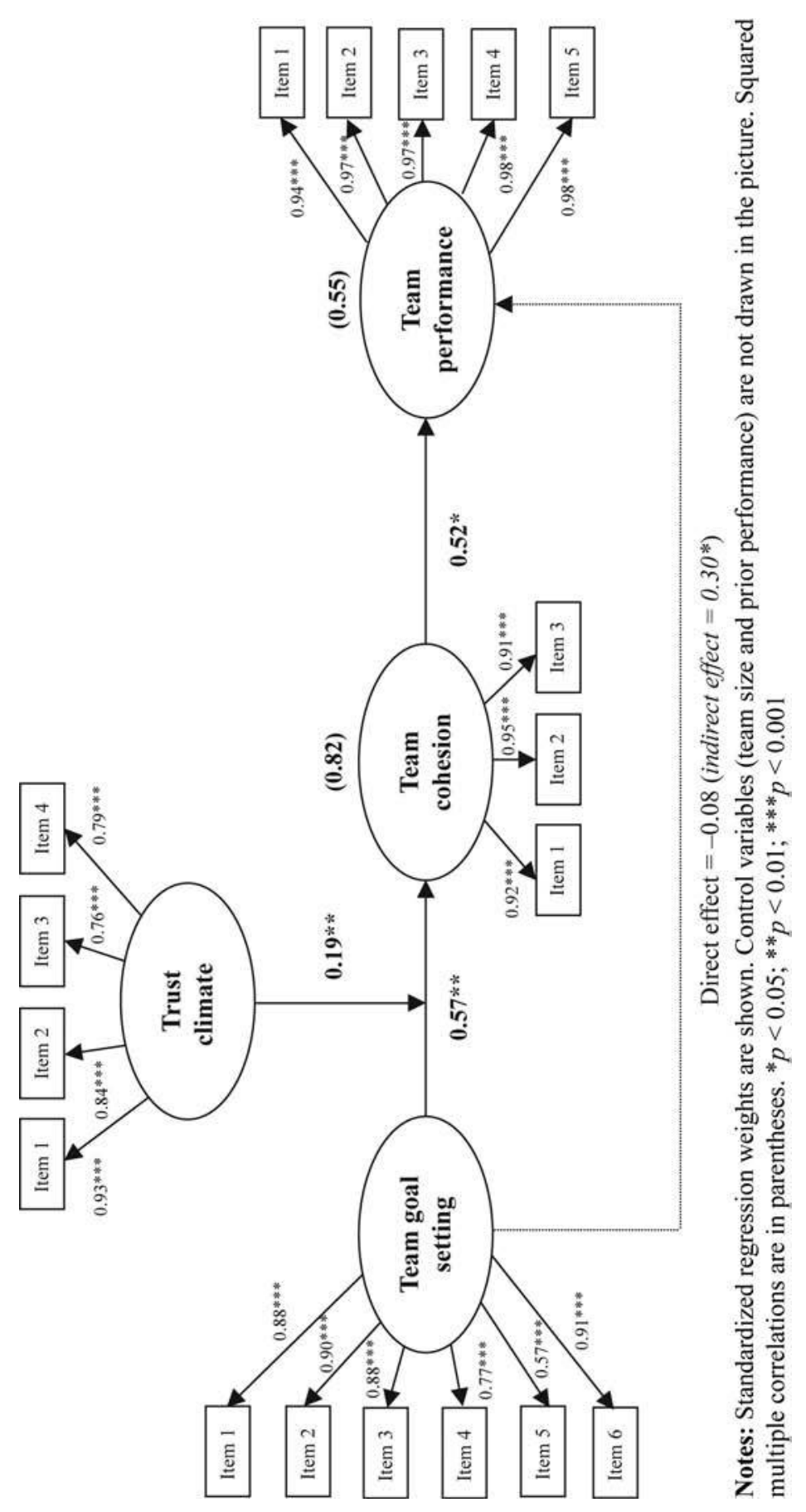

The role of trust in VTs

603

Figure 2. Structural model results 
JMP

27,6

604 measurement errors and simultaneously testing all hypothesized relationships (Bagozzi and $\mathrm{Yi}, 1989)$. Our hypotheses include both moderation and mediating relationships. In order to test for the moderation, we employed the procedure described by Little et al. (2006). To ease the interpretation, we also graphically plotted the interaction results (Aiken and West, 1991). We tested the mediated relations using bootstrapping procedures, following the recommendations by Cheung and Lau (2008). Finally, we specified three models in SEM with high values $(+1 S D)$, low values $(-1 S D)$ as well as very low values $(-2 S D)$ of the moderator to inspect the conditional mediated relations.

\section{Results}

Table I shows the intercorrelation of the study's constructs. As proposed by H1, team goal setting is positively related with team cohesion $(r=0.81, p<0.001)$. In addition, the expected positive association between team cohesion and performance is evident as proposed in $H 3(r=0.49, p<0.001)$. Team performance is also positively correlated with team goal setting $(r=0.49, p<0.001)$. Concerning the control variables, team size is positively related to all central study variables and initial team potential is positively related to team performance $(r=0.39, p<0.001)$. To not confound our results by impotent control variables (Becker, 2005) and to limit the degrees of freedom, we decided to include only those two significant controls in further analyzes.

As the correlation between team goal setting and team cohesion was comparatively high $(r=0.81, p<0.001)$, we conducted two additional CFAs to investigate the discriminatory validity of the two construct. In the first model, we specified the expected separate measurement structure of the two constructs and received an acceptable model fit $(\chi 2=67, \mathrm{df}=26 ; p<0.001 \mathrm{CFI}=0.91, \mathrm{IFI}=0.91$, SRMR $=$ 0.057 , RMSEA $=0.124$ ). As an alternative model, we specified a solution with all cohesion and goal setting items loading on one common factor. This model had a significant worse fit $(\chi 2=0.106, \mathrm{df}=27 ; p<0.001 \mathrm{CFI}=0.83, \mathrm{IFI}=0.83, \mathrm{SRMR}=$ 0.074 , RMSEA $=0.264$ ), indicating sufficient discriminatory validity between the two constructs and also indicating a low likelihood of a potential multicollinearity bias.

The assumed moderated-mediated structural model showed good fit properties $(\chi 2=291, \mathrm{df}=215 ; p<0.001 \mathrm{CFI}=0.96, \mathrm{IFI}=0.97, \mathrm{SRMR}=0.075, \mathrm{RMSEA}=$ 0.070). Figure 2 shows results for the proposed structural relationships.

Supporting $H 1$, team goal setting is positively related to team cohesion $(\beta=0.57$, $t=4.55, p<0.006)$. H2 is also supported by the significant relation of the interaction term $(\beta=0.19, t=2.63, p<0.009)$ to team cohesions. To better interpret this moderation relationship, a graphical plotting was carried out (see Figure 3), further supporting $H 2$ due to the significantly more distinct positive relation of team goal setting and team cohesion when team trust is high rather than low.

In line with $H 3$, a positive association between team cohesion and team performance was found $(\beta=0.57, t=2.35, p<0.019)$. Furthermore, the linkage between team goal setting and team performance was found to be non-significant $(\beta=-0.08, t=-0.36$, $p=\mathrm{ns}$ ), indicating a fully mediating association between team goal setting and performance transmitted by team cohesion.

In a further step, we also tested significance of the mediated association between goal setting and performance with bootstrapping procedures (1,000 bootstrap samples were used). The result showed a significantly mediated relation for mean values of team trust $(\beta=0.30, z=1.84, p<0.033)$. In a last step, we specified three additional 


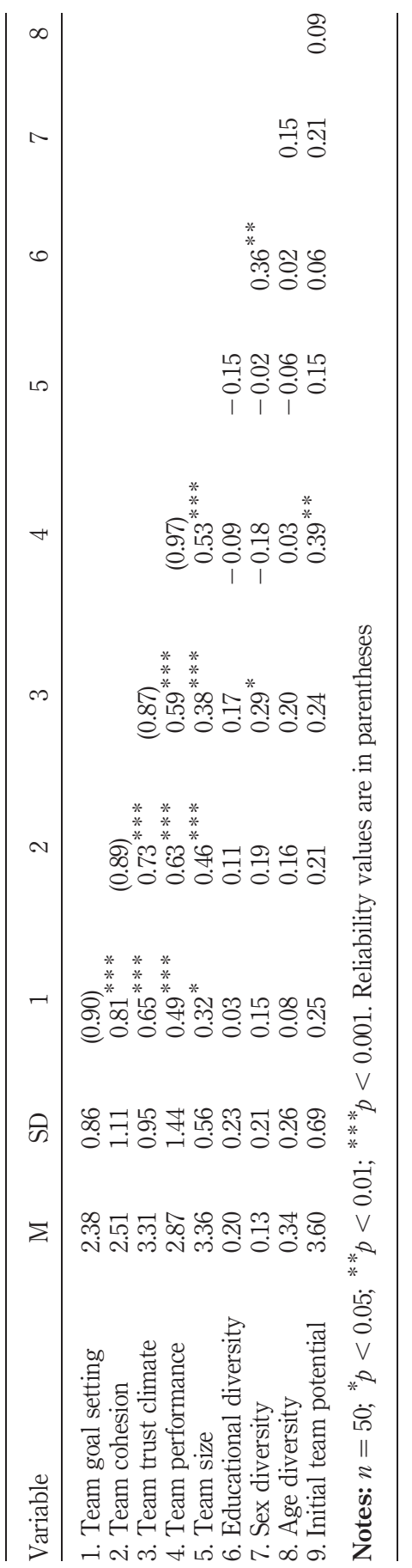

\section{The role of trust in VTs}

605

Table I. Means, standard deviations, and intercorrelations 
JMP

27,6

606

Figure 3.

Moderation analysis

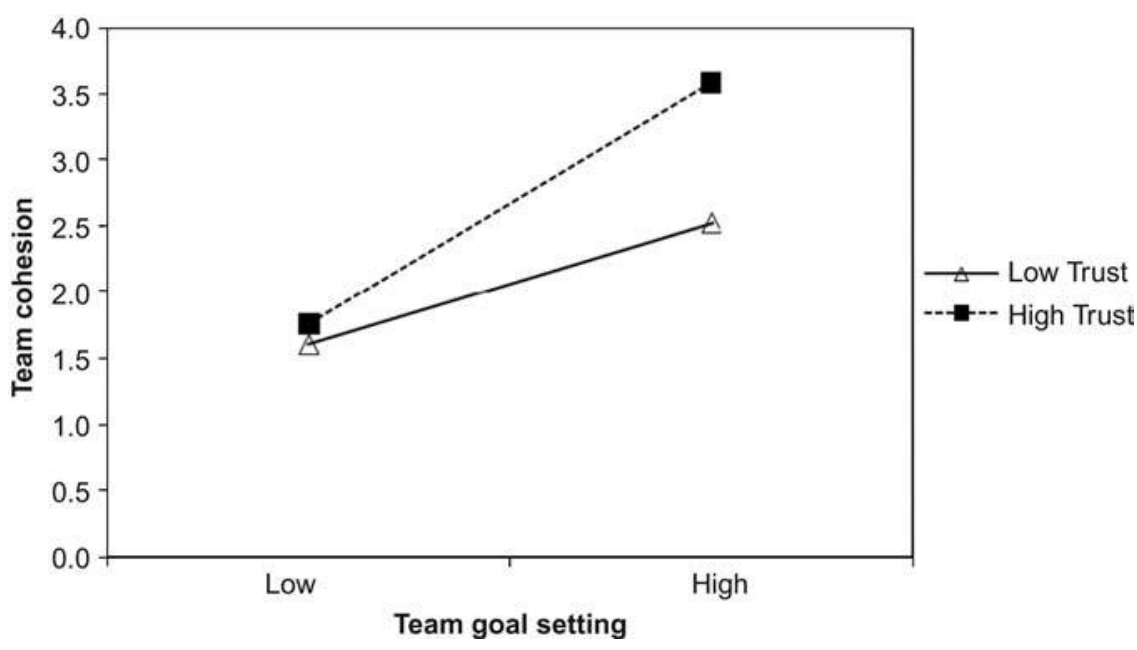

models that had either high values of trust $(+1 S D)$, low values of trust $(-1 S D)$, or very low values of trust $(-2 S D)$ as moderators, to directly test the conditional mediating relation. As expected, the mediated linkage was much stronger at high values of trust $(\beta=0.44, z=1.88, p<0.03)$ compared to low values of trust $(\beta=0.24, z=1.68$, $p<0.046)$, supporting $H 4)$. At very low values of trust $(-2 S D)$ the mediation was even not significant anymore $(\beta=0.20, z=1.04, p=\mathrm{ns})$.

\section{Discussion}

The present study investigated the interplay of several distinct factors relating to VT performance. Although the relation between individual process factors and VT performance was already investigated, the underlying dynamics in VTs have not yet been tested in a more sophisticated, theoretically grounded model (Martins et al., 2004). The current study examined the relationship amongst team goal setting and team cohesion and their sequential relationship with performance, depending on the level of trust climate.

Based on prior theoretical and empirical findings, team goal setting was expected to positively relate to team cohesion (H1), which is positively connected to team performance $(H 3)$. In addition, the relationship between team goal setting and team cohesion in VTs was expected to be more explicit under the boundary condition of a team trust climate (H2). In a high team trust climate, team members feel more secure to invest in social relationships and actions with other team members, meaning team goals can better translate into team cohesion. In contrast, in a climate of low team trust, team members do not have the confidence that their colleagues act according to their team goals; thus, they might not develop team cohesion based on team goals. The reduction of uncertainty and, consequently, the feeling that taking risks is possible as fostered by team trust climate - are crucial for the development and ultimate performance of a VT (Peters and Manz, 2007; Zolin et al., 2004; Rico et al., 2008). Taken together, the study supported a moderated-mediation hypothesis (Preacher et al., 2007), with goal setting positively relating to team performance, mediated through team cohesion while this mediated linkage depends on the trust climate within the respective team. Thus, trust climate seems to be a boundary condition that helps virtual entities to 
function as virtual teams that are socially integrated and show high performance rather than being loose and also lower performing virtual groups.

\section{Theoretical implications}

The findings reported here extend the virtual team literature in at least two unique ways. First, the current study goes beyond prior studies that solely considered single (and mostly direct) antecedents of VT performance (e.g. Geister et al., 2006; van Vianen and De Dreu, 2001). This study, in contrast, develops a complex process model, incorporating moderating and mediating mechanisms as suggested by Martins $e t$ al. (2004). Specifically, this study identified team cohesion as an important emergent state mediating the relationship between team goal setting and team performance. However, this relationship is contingent upon another crucial emergent state - namely, a VT's trust climate. In sum, this study used theoretical propositions on team processes and emergent states from the general team literature (Mathieu et al., 2008) and tested them with VTs. Thus, the tested model is a further step toward better understanding the development process of virtual teams due to a focus on central group dynamics (Driskell et al., 2003). Future studies may apply these results to further advance the knowledge on VT team processes and outcomes.

Second, these results make a decisive contribution to the role of trust in VT research. Thus far, trust has been researched as an antecedent (Staples and Webster, 2008; Liu et al., 2008) or mediating variable (Garrison et al., 2010) with regard to VT performance. The current study follows the conceptual reasoning of Dirks and Ferrin (2001) and adds an important aspect by establishing the trust climate as a prominent boundary condition for VT success. Thus, the arguments from attribution theory (Jarvenpaa et al., 2004) that trust elicits more certainty and less ambiguity in (virtual) relationships not only count for a direct association with team processes and outcomes but are likewise a good explanation for a fruitful environment that positively connects goal setting with team cohesion and ultimately team performance. Future studies might pick up on this moderating role of trust in VT research and, for instance, consider it not only as a boundary condition for positive processes as in the current study but also as a buffer for negative states such as conflicts (Jehn et al., 1999).

\section{Practical and societal implications}

The findings suggest a number of implications for the management of VTs. First and foremost, the study supports the crucial role of a trust climate for VTs (Jarvenpaa et al., 1998; Peters and Manz, 2007; Zolin et al., 2004). Thus, managers should emphasize the development of team trust at early stages of collaboration in a VT as already suggested by the theory of "swift trust" put forth by Meyerson et al. (1996). Swift trust means that at the beginning of a team's interaction, it is important for trust to be imported from other settings so that work in a trustworthy environment immediately starts (Jarvenpaa and Leidner, 1999). One way to achieve high levels of trust is through face-to-face meetings during the initial "courtship" period of a VT's life cycle (Coutu, 1998; Suchan and Hayzak, 2001). As a second option, other research suggests that the number and frequency of virtual interactions are also central for trust development (Iacono and Weisband, 1997). Following this logic, any initiation of interactions between VT team members can be interpreted as some form of trust that is further strengthened if other team members respond to it. Furthermore, the current results imply that team goal

\section{The role of trust in VTs}

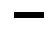


JMP

27,6

608 setting should also be considered as an important starting point for VTs. Goal setting should not be disregarded in VTs as it is positively associated with team cohesion, in turn related with performance. Thus, initial team meetings that are either virtual or face-to-face should be arranged to reach a high commitment to team goals.

In terms of the study's societal impact, these managerial implications should also help companies to care for productive VTs increasing their overall economic and societal contribution. As globalization is still increasing in many industry sectors, a successful management of VTs is a crucial factor for the overall economic prosperity of all industrialized societies. The results of this study are, thus, a further step to develop VTs that not only have satisfied and motivated members but also favor high performance levels for the sake of the whole society.

\section{Limitations and future research}

Characteristic to empirical research in general, this study has a number of limitations that should be considered when interpreting the results. First, although the current study unlike many other studies on VTs that rely only on lab data (Martins et al., 2004) - took place in a real company in a vocational setting, the specific composition of the sample limits the generalizability of the findings. Thus, future studies should try to replicate these results with VTs consisting of employees from all hierarchal levels of the company. Additional research might also try to survey VTs with team members from different cultural backgrounds given that cultural diversity has been reported to be important for VT team processes and outcomes (Maznevski and Chudoba, 2000; Tan et al., 1998).

Second, a common source bias (Podsakoff et al., 2003) might be a potential problem for some of the observed relationships in this study as some information for the constructs were obtained from similar employees. However, for $H 2$ and $H 3$, such an inflation of the results is relatively unlikely. Concerning H2, Evans (1985) demonstrated through a Monte Carlo simulation that it is improbable to draw an incorrect inference caused by artifactual common method inference in the instance of testing for interaction terms. In addition, for $H 3$, with the VT processes/performance relationship as one of the main contributions, a common source bias was excluded due the two different points in time for data collection. Thus, with H1, only a minor part of the proposed model is likely to be affected by same source bias, suggesting that no systematic distortion of the study's results occurred.

Beyond these limitations, the current study suggests several interesting directions for future research. With the testing of a theoretically grounded model, this study provided the basis for further investigations on more complex models for VT performance. Team goal setting and team cohesion was shown to be related to VT performance in the trust climate, which concurs with prior research on the importance of these factors (e.g. Beal et al., 2003; Jarvenpaa et al., 2004). To further extend this model, it could be interesting to include other input or process factors (Marks et al., 2001), such as team learning behavior (Ellis et al., 2004) or the competencies of the individual members (Hertel et al., 2006).

In addition, other studies have shown that the type of tasks that VTs undertake moderates the outcomes among work groups in general (Stewart and Barrick, 2000; Wageman, 1995), including VTs (Majchrzak et al., 2000). It may be interesting to consider task type in future studies on the goal setting/performance relationship moderated by trust in order to test whether the relationship remains dependent on the 
task meaningfulness, the team's autonomy within the organization, and the level of intra-group coordination (Stewart, 2006).

In sum, this study provides further empirical knowledge on the development of VTs. The moderated-mediation model explaining the mediating relationship between team goal setting and performance transmitted through team cohesion, which is dependent upon the level of trust climate, should serve as the foundation for other research investigating VTs. It is hoped that other scholars will build on this study to increase knowledge of $\mathrm{V}$ processes and performance - both for the team literature and even more importantly to successfully manage the increasing number of VTs in real business settings.

\section{References}

Aiken, L.S. and West, S.G. (1991), Multiple Regression: Testing and Interpreting Interactions, Sage, Thousand Oaks, CA.

Ancona, D.G. and Caldwell, D.F. (1992), "Bridging the boundary: external activity and performance in organizational teams", Administrative Science Quarterly, Vol. 37 No. 4, pp. 634-65.

Bagozzi, R.P. and Yi, Y. (1989), "On the use of structural equation models in experimental designs", Journal of Marketing Research, Vol. 26 No. 3, pp. 271-84.

Bantel, K.A. and Jackson, S.E. (1989), "Top management and innovations in banking - does the composition of the top team make a difference", Strategic Management Journal, Vol. 10, S1, pp. 107-24.

Barrick, M.R., Stewart, G.L., Neubert, M.J. and Mount, M.R. (1998), "Relating member ability and personality to work-team processes and team effectiveness", Journal of Applied Psychology, Vol. 83 No. 3, pp. 377-91.

Beal, D.J., Cohen, R.R., Burke, M.J. and McLendon, C.L. (2003), “Cohesion and performance in groups: a meta-analytic clarification of construct relations", Journal of Applied Psychology, Vol. 88 No. 6, pp. 989-1004.

Becker, T.E. (2005), "Potential problems in the statistical control of variables in organizational research: a qualitative analysis with recommendations", Organizational Research Methods, Vol. 8 No. 3, pp. 274-89.

Bell, B.S. and Kozlowski, S.W.J. (2002), "A typology of virtual teams: implications for effective leadership”, Group \& Organization Management, Vol. 27 No. 1, pp. 14-49.

Bentler, P.M. (1990), “Comparative fit indices in structural models", Psychological Bulletin, Vol. 107 No. 2, pp. 238-46.

Blackburn, R., Furst, S. and Rosen, B. (2003), "Building a winning virtual team", in Gibson, C. and Cohen, E.G. (Eds), Virtual Teams that Work: Creating Conditions for Virtual Team Effectiveness, Jossey Bass, San Francisco, CA, pp. 95-120.

Blau, P. (1977), Inequality and Heterogeneity, Free Press, New York, NY.

Bliese, P.D. (2000), "Within-group agreement, non-independence, and reliability: implications for data aggregation and analysis", in Klein, K.J. and Kozlowski, S.W.J. (Eds), Multilevel Theory, Research, and Methods in Organizations: Foundations, Extensions, and New Directions, Jossey-Bass, San Francisco, CA, pp. 349-81.

Bollen, K.A. (1989), Structural Equation with Latent Variables, Wiley, New York, NY.

Browne, M. and Cudeck, R. (1993), "Alternate ways of assessing model fit”, in Bollen, K.A. and Long, J.S. (Eds), Testing Structural Equations Models, Sage Publications, Newbury Park, CA, pp. 136-62.

\section{The role of trust in VTs}

609 
JMP

27,6

610

Bunderson, J.S. and Sutcliffe, K.M. (2002), "Comparing alternative conceptualizations of functional diversity in management teams: process and performance effects", Academy of Management Journal, Vol. 45 No. 5, pp. 875-93.

Castro, S.L. (2002), "Data analytic methods for the analysis of multilevel questions: a comparison of intraclass correlation coefficients, rwg(j), hierarchical linear modeling, within- and between-analysis, and random group resampling", The Leadership Quarterly, Vol. 13 No. 1, pp. 69-93.

Chang, A. and Bordia, P. (2001), "A multidimensional approach to the group cohesion-group performance relationship”, Small Group Research, Vol. 32 No. 4, pp. 379-405.

Chen, F., Curran, P.J., Bollen, K.A., Kirby, J. and Paton, P. (2008), "An empirical evaluation of the use of fixed cutoff points in RMSEA test statistic in structural equation models", Sociological Methods Research, Vol. 36 No. 4, pp. 462-94.

Cheung, G.W. and Lau, R.S. (2008), "Testing mediation and suppression effects of latent variables: bootstrapping with structural equation models", Organizational Research Methods, Vol. 11 No. 2, pp. 296-325.

Coutu, D.L. (1998), “Organization: trust in virtual teams”, Harvard Business Review, Vol. 76 No. 1, pp. 20-1.

Curşeu, P.L. (2006), "Emergent states in virtual teams: a complex adaptive systems perspective", Journal of Information Technology, Vol. 21 No. 4, pp. 249-61.

DeRosa, D.M., Hantula, D.A., Kock, N. and D’Arcy, J. (2004), “Trust and leadership in virtual teamwork: a media naturalness perspective”, Human Resource Management, Vol. 43 Nos 2-3, pp. 219-32.

DeSanctis, G. and Monge, P. (1999), "Communication processes for virtual organizations", Organization Science, Vol. 10 No. 6, pp. 693-703.

De Souza, G. and Klein, H.J. (1995), "Emergent leadership in the group goal-setting process", Small Group Research, Vol. 26 No. 4, pp. 475-96.

Dirks, K.T. and Ferrin, D.L. (2001), "The role of trust in organizational settings", Organizational Science, Vol. 12 No. 4, pp. 405-67.

Driskell, J.E., Radtke, P.H. and Salas, E. (2003), "Virtual teams: effects of technological mediation on team performance", Group Dynamics: Theory, Research, and Practice, Vol. 7 No. 4, pp. 297-323.

Ellis, A.P.J., Hollenbeck, J.R., Ilgen, D.R., Porter, C.O.L.H., West, B.J. and Moon, H. (2004), "Team learning: collectively connecting the dots", Journal of Applied Psychology, Vol. 88 No. 5, p. 821.

Evans, M.G. (1985), "A Monte-Carlo Study of the effects of correlated method variance in moderated multiple-regression analysis", Organizational Behavior and Human Decision Processes, Vol. 36 No. 3, pp. 305-23.

Furst, S., Blackburn, R. and Rosen, B. (1999), "Virtual team effectiveness: a proposed research agenda”, Information Systems Journal, Vol. 9 No. 4, pp. 249-69.

Furst, S.A., Reeves, M., Rosen, B. and Blackburn, R.S. (2004), "Managing the life cycle of virtual teams", Academy of Management Executive, Vol. 18 No. 2, pp. 6-20.

Garrison, G., Wakefield, R.L., Xu, X. and Kim, S.H. (2010), "Globally distributed teams: the effect of diversity on trust, cohesion and individual performance", The Data Base for Advances in Information Systems, Vol. 41 No. 3, pp. 27-48.

Geister, S., Konradt, U. and Hertel, G. (2006), "Effects of process feedback on motivation, satisfaction, and performance in virtual teams", Small Group Research, Vol. 37 No. 5, pp. 459-89. 
Gillam, C. and Oppenheim, C. (2006), "Review article: reviewing the impact of virtual teams in the information age", Journal of Information Science, Vol. 32 No. 2, pp. 160-75.

Hackman, J.R. (1987), “The design of work teams”, in Lorsch, J. and William, J. (Eds), Handbook of Organizational Behavior, Prentice Hall, Englewood Cliffs, NJ, pp. 315-42.

Hackman, J.R. and Morris, C.G. (1975), "Group task, group interaction process, and group performance effectiveness: a review and proposed integration”, in Berkowitz, L. (Ed.), Advances in Experimental Social Psychology, Academic Press, New York, NY, pp. 45-99.

Harrison, D.A. and Klein, K.J. (2007), "What's the difference? Diversity constructs as separation, variety, or disparity in organizations", Academy of Management Review, Vol. 32 No. 4, pp. 1199-228.

Henttonen, K. and Blomqvist, K. (2005), "Managing distance in a global virtual team: the evolution of trust through technology-mediated relational communication", Strategic Change, Vol. 14 No. 2, pp. 107-19.

Hertel, G., Geister, S. and Konradt, U. (2005), "Managing virtual teams: a review of current empirical research", Human Resource Management Review, Vol. 15 No. 1, pp. 69-95.

Hertel, G., Konradt, U. and Orlikowski, B. (2004), "Managing distance by interdependence: goal setting, task interdependence, and team-based rewards in virtual teams", European Journal of Work \& Organizational Psychology, Vol. 13 No. 1, pp. 1-28.

Hertel, G., Konradt, U. and Voss, K. (2006), "Competencies for virtual teamwork: development and validation of a web-based selection tool for members of distributed teams", European Journal of Work \& Organizational Psychology, Vol. 15 No. 4, pp. 477-504.

Holton, J.A. (2001), "Building trust and collaboration in a virtual team", Team Performance Management: An International Journal, Vol. 7 Nos 3/4, pp. 36-47.

Horwitz, S.K., Bravington, D. and Silvis, U. (2006), "The promise of virtual teams: identifying key factors in effectiveness and failure", Journal of European Industrial Training, Vol. 30 No. 6, pp. 472-94.

Hu, L.T. and Bentler, P.M. (1998), "Fit indices in covariance structure modeling: sensitivity to underparameterized model misspecification”, Psychological Methods, Vol. 3 No. 4, pp. 424-53.

Huang, W.W., Wei, K.-K., Watson, R.T. and Tan, B.C.Y. (2002), "Supporting virtual team-building with a GSS: an empirical investigation”, Decision Support Systems, Vol. 34 No. 4, pp. 359-67.

Iacono, C.S. and Weisband, S. (1997), "Developing trust in virtual teams", paper presented at the Hawaii International Conference on Systems Sciences, Hawaii.

James, L.R., Demaree, R.G. and Wolf, G. (1984), "Estimating within-group interrater reliability with and without response bias", Journal of Applied Psychology, Vol. 69 No. 1, pp. 85-98.

Jarvenpaa, S.L. and Leidner, D.E. (1999), "Communication and trust in global virtual teams", Organization Science, Vol. 10 No. 6, pp. 791-816.

Jarvenpaa, S.L., Knoll, K. and Leidner, D.E. (1998), "Is anybody out there?", Journal of Management Information Systems, Vol. 14 No. 4, pp. 29-64.

Jarvenpaa, S.L., Shaw, T.R. and Staples, D.S. (2004), "Toward contextualized theories of trust: the role of trust in global virtual teams", Information Systems Research, Vol. 15 No. 3, pp. 250-67.

Jehn, K.A., Northcraft, G.B. and Neale, M.A. (1999), "Why differences make a difference: a field study of diversity, conflict, and performance in workgroups", Administrative Science Quarterly, Vol. 44 No. 4, pp. 741-63.

\section{The role of trust in VTs}

611 
JMP

27,6

\section{2}

Johnson, D.W. and Johnson, F.P. (1987), Joining Together: Group Therapy and Group Skills, Prentice Hall, Englewood Cliffs, NJ.

Katzenbach, J.R. and Smith, D.K. (1993), The Wisdom of Teams: Creating the High Performance Organisation, Harvard Business Press, Boston, MA.

Kirkman, B.L., Rosen, B., Tesluk, P.E. and Gibson, C.B. (2004), "The impact of team empowerment on virtual team performance: the moderating role of face-to-face interaction", Academy of Management Journal, Vol. 47 No. 2, pp. 175-92.

Klein, H.J. and Mulvey, P.W. (1995), "Two investigations of the relationships among group goals, goal commitment, cohesion, and performance", Organizational Behavior and Human Decision Processes, Vol. 61 No. 1, pp. 44-53.

Kozlowski, S.W.J. and Bell, B.S. (2003), "Work groups and teams in organizations", in Borman, W.C., Ilgen, D.R. and Klimoski, R.J. (Eds), Handbook of Psychology, Vol. 12: Industrial and Organizational Psychology, Wiley, New York, NY, pp. 333-75.

Kozlowski, S.W.J. and Klein, K.J. (2000), "A multilevel approach to theory and research in organizations: contextual, temporal, and emergent processes", in Klein, K.J. and Kozlowski, S.W.J. (Eds), Multilevel Theory, Research, and Methods in Organizations: Foundations, Extensions, and New Directions, Jossey-Bass, San Francisco, CA, pp. 3-90.

Li, X., Valacich, J.S. and Hess, T.J. (2004), "Predicting user trust in information systems: a comparison of competing trust models", Proceedings of the 37th Hawaii International Conference on System Sciences.

Little, T.D., Bovaird, J.A. and Widaman, K.F. (2006), "On the merits of orthogonalizing powered and product terms: implications for modeling latent variable interactions", Structural Equation Modeling, Vol. 13 No. 4, pp. 479-519.

Liu, X., Magjuka, R.J. and Lee, S.-H. (2008), “An examination of the relationship among structure, trust, and conflict management styles in virtual teams", Performance Improvement Quarterly, Vol. 21 No. 1, pp. 77-93.

Majchrzak, A., Rice, R.E., Malhotra, A., King, N. and Ba, S. (2000), "Technology adaptation: the case of a computer-supported inter-organizational virtual team”, MIS Quarterly, Vol. 24 No. 4, pp. 569-600.

Marks, M.A., Mathieu, J.E. and Zaccaro, S.J. (2001), "A temporally based framework and taxonomy for team processes”, Academy of Management Review, Vol. 26 No. 3, pp. 356-76.

Martins, L.L., Gilson, L.L. and Maynard, M.T. (2004), "Virtual teams: what do we know and where do we go from here?”, Journal of Management, Vol. 30 No. 6, pp. 805-35.

Mathieu, J., Maynard, M.T., Rapp, T. and Gilson, L. (2008), “Team effectiveness 1997-2007: a review of recent advancements and a glimpse into the future", Journal of Management, Vol. 34 No. 3, pp. 410-76.

Mayer, R.C., Davis, J.H. and Schoorman, F.D. (1995), "An integrative model of organizational trust”, Academy of Management Review, Vol. 20 No. 3, pp. 709-34.

Maznevski, M.L. and Chudoba, K.M. (2000), "Bridging space over time: global virtual team dynamics and effectiveness", Organization Science, Vol. 11 No. 5, pp. 473-92.

Meyerson, D., Weick, K.E. and Kramer, R.M. (1996), "Swift trust and temporary groups", in Kramer, R.M. and Tyler, T.R. (Eds), Trust in Organizations: Frontiers of Theory and Research, Sage Publications, Thousand Oaks, CA, pp. 166-95.

Mitchell, A. and Zigurs, I. (2009), "Trust in virtual teams: solved or still a mystery", The Data Base for Advances in Information Systems, Vol. 40 No. 3, pp. 61-83. 
Montoya-Weiss, M.M., Massey, A.P. and Song, M. (2001), "Getting it together: temporal coordination and conflict management in global virtual teams", Academy of Management Journal, Vol. 44 No. 6, pp. 1251-62.

Mullen, B., Copper, C., Cox, P.W., Fraser, C., Hu, L., Meisler, A., Smith, C. and Symons, C. (1991), "Boundaries around group-interaction - a meta analytical integration of the effects of group size", Journal of Social Psychology, Vol. 131 No. 2, pp. 271-83.

Peters, L.M. and Manz, C.C. (2007), "Identifying antecedents of virtual team collaboration", Team Performance Management, Vol. 13 Nos 3/4, pp. 117-29.

Podsakoff, P.M., MacKenzie, S.B., Lee, J.-Y. and Podsakoff, N.B. (2003), "Common method biases in behavioral research: a critical review of the literature and recommended remedies", Journal of Applied Psychology, Vol. 88 No. 5, pp. 879-903.

Porter, T.W. and Lilly, B.S. (1996), "The effects of conflict, trust, and task commitment on project team performance", International Journal of Conflict Management, Vol. 7 No. 4, pp. 361-76.

Preacher, K.J., Rucker, D.D. and Hayes, A.F. (2007), "Addressing moderated mediation hypotheses: theory, methods, and prescriptions”, Multivariate Behavioral Research, Vol. 42 No. 1, pp. 185-227.

Rack, O., Ellwart, T., Hertel, G. and Konradt, U. (2011), "Team-based rewards in computer-mediated groups", Journal of Managerial Psychology, Vol. 26 No. 5, pp. 419-38.

Rico, R., Sánchez-Manzanares, M., Gil, F. and Gibson, C. (2008), "Team implicit coordination processes: a team knowledge-based approach", The Academy of Management Review, Vol. 33 No. 1, pp. 163-84.

Sarker, S. and Valacich, J.S. (2003), "Virtual team trust: instrument development and validation in an IS educational environment", Information Resources Management Journal (IRMJ), Vol. 16 No. 2, pp. 35-55.

Staples, D.S. and Webster, J. (2008), "Exploring the effects of trust, task interdependence and virtualness on knowledge sharing in teams", Information Systems Journal, Vol. 18 No. 6, pp. $617-40$.

Stewart, G.L. (2006), "A meta-analytic review of relationships between team design features and team performance”, Journal of Management, Vol. 32 No. 1, pp. 29-54.

Stewart, G.L. and Barrick, M.R. (2000), "Team structure and performance: assessing the mediating role of intrateam process and the moderating role of task type", The Academy of Management Journal, Vol. 43 No. 2, pp. 135-48.

Suchan, J. and Hayzak, G. (2001), "The communication characteristics of virtual teams: a case study”, IEEE Transactions on Professional Communication, Vol. 44, pp. 174-86.

Tan, B.C.Y., Wei, K.K., Watson, R.T., Clapper, D.L. and McLean, E.R. (1998), “Computer-mediated communication and majority influence: assessing the impact in an individualistic and a collectivistic culture”, Management Science, Vol. 44 No. 9, pp. 1263-78.

Townsend, A.M., DeMarie, S.M. and Hendrickson, A.R. (1998), "Virtual teams: technology and the workplace of the future", The Academy of Management Executive, Vol. 12 No. 3, pp. 17-29.

Van den Bossche, P., Gijselaers, W.H., Segers, M. and Kirschner, P.A. (2006), "Social and cognitive factors driving teamwork in collaborative learning environments: team learning beliefs and behaviors", Small Group Research, Vol. 37 No. 5, pp. 490-519.

van Knippenberg, D. and Schippers, M.C. (2007), "Work group diversity", Annual Review of Psychology, Vol. 58 No. 1, pp. 515-41.

van Vianen, A.E.M. and De Dreu, C.K.W. (2001), "Personality in teams: its relationship to social cohesion, task cohesion, and team performance", European Journal of Work and Organizational Psychology, Vol. 10 No. 2, pp. 97-120.

\section{The role of trust in VTs}

613 
JMP

27,6

614

Wageman, R. (1995), "Interdependence and group effectiveness", Administrative Science Quarterly, Vol. 40 No. 1, pp. 145-80.

Wegge, J. (2000), "Participation in group goal setting: some novel findings and a comprehensive model as a new ending to an old story", Applied Psychology: An International Review, Vol. 49 No. 3, pp. 498-516.

Wegge, J., Roth, C., Neubach, B., Schmidt, K.H. and Kanfer, R. (2008), “Age and gender diversity as determinants of performance and health in a public organization: the role of task complexity and group size”, Journal of Applied Psychology, Vol. 93 No. 6, pp. 1301-13.

Wilson, J.M., Straus, S.G. and McEvily, B. (2006), "All in due time: the development of trust in computer-mediated and face-to-face teams”, Organizational Behavior and Human Decision Processes, Vol. 99 No. 1, pp. 16-33.

Zellmer-Bruhn, M. and Gibson, C. (2006), "Multinational organization context: implications for team learning and performance", The Academy of Management Journal, Vol. 49 No. 3, pp. 501-18.

Zolin, R., Hinds, P.J., Fruchter, R. and Levitt, R. (2004), "Interpersonal trust in cross-functional, geographically distributed work: a longitudinal study", Information and Organization, Vol. 14 No. 1, pp. 1-26.

\section{Appendix A}

Measurement items:

Team cohesion was measured with the following three items by Chang and Bordia (2001):

(1) the team is united in trying to reach its goal for performance;

(2) everyone tries to help if members have problems; and

(3) team members communicate freely about each other's responsibility.

Team performance was measured with five items based on a scale by Zellmer-Bruhn and Gibson (2006):

(1) this team achieves its goals;

(2) this team accomplishes its objectives;

(3) this team meets the requirements set for it;

(4) this team serves the purpose it is intended to serve; and

(5) this team fulfills its mission.

\section{About the authors}

Taiga Brahm is an Assistant Professor for the Development of Higher Education at the University of St Gallen, Switzerland. Her current research interests include virtual teams, team learning, interaction processes in virtual and traditional teams as well as educational development in higher education. Taiga Brahm is the corresponding author and can be contacted at: taiga.brahm@unisg.ch

Florian Kunze is a Senior Research Associate at the University of St Gallen, Switzerland. His current research interests include consequences of the demographic change for companies, within-group processes and dynamics in work teams and organizations, discrimination and stereotyping due to demographic characteristics, and leadership research.

To purchase reprints of this article please e-mail: reprints@emeraldinsight.com Or visit our web site for further details: www.emeraldinsight.com/reprints 
This article has been cited by:

1. Joana Kuntz, Abigail Roberts. 2014. Engagement and identification. Strategic Outsourcing: An International Journal 7:3, 253-274. [Abstract] [Full Text] [PDF]

2. Han-Ping Fung, Heng-Loke Siow. 2014. Relationship of Team Outcome Factors and Project Performance as Perceived by Project Managers in Malaysia - A Mixed Methods Study. International Journal of Multiple Research Approaches 3876-3902. [CrossRef]

3. Faizuniah Pangil, Joon Moi Chan. 2014. The mediating effect of knowledge sharing on the relationship between trust and virtual team effectiveness. Journal of Knowledge Management 18:1, 92-106. [Abstract] [Full Text] [PDF]

4. Stefan Krumm, Katrin Terwiel, Guido Hertel. 2013. Challenges in Norm Formation and Adherence. Journal of Personnel Psychology 12, 33-44. [CrossRef] 